Chapter 4.

\title{
Principles of practical implementation of the constructivist blended learning approach to teaching English for Specific Purposes at tertiary schools
}

The principles in questions are required for setting clear and accurate reference points that are needed for practical implementation of the constructivist blended learning approach. They are kinds of teaching practice-oriented guidelines as to what and how should be done in the practical process of teaching and learning to provide for the successful learning outcomes of that entire process. The principles: 1) practically regulate teaching/learning content selection in order to make the instruction genuinely professional content based (theme-based); 2) practically regulate the use of experiential interactive learning activities in the ESP course; 3) practically prepare students for working on the Internet, and 4) therefore, form a firm foundation for developing the organizational model of every particular ESP course which finalizes the practical development of such a course as a whole.

It has already been said in the Introduction that five of such practical principles have been postulated by us. They include:

1. the principle of systematizing professional information in the coursebook and course of English for Specific Purposes;

2. the principle of authenticity of students' learning activities and learning communication;

3. the principle of authenticity of learning materials;

4. the principle of integrating English speaking, listening, reading, and writing in the learning process;

5. the principle of developing students' informative competence in English.

The first and the third of these principles serve for ensuring the practical implementation of such a basic feature of the constructivist blended learning approach as content-based (theme-based) instruction. The second principle is also partly used for achieving the same goal. However, together with the fourth principle, it provides practical conditions for implementing experiential interactive teaching/learning as well. Finally, the fifth principle is directed at creating the best prerequisites for Internet technologies' use in the teaching/learning process.

Each of the five principles is separately discussed below. 


\section{The principle of systematizing professional information in the coursebook and course of English for Specific Purposes}

This principle means that an ESP coursebook and an ESP course organized on the basis of that coursebook must be designed in such a way as not to be just a collection of professionally oriented themes, materials, and activities for learning. It is supposed to be a more or less complete summary in English of the fundamental and systematized notions from the students' future profession/specialty embracing all the basic issues of future specialist's professional activities.

The requirement of introducing this principle is due to the specificity of such a feature of the constructivist approach as content-based, and particularly themebased, instruction. That instruction, as shown in Chapter 2, is called upon to provide students with a more or less complete and generalized 'picture', or synopsis, of their future profession through the medium of the target language. The complete and generalized picture cannot be created if the ESP coursebook (and, consequently, the ESP course) is 'a heap' of fragmentary facts and fragmentary unsystematically selected information concerning the learners' future profession - as it often happens in practice. The required 'big picture' of future profession 'painted' by means of the target language can be obtained by students only if their ESP course provides them with a systemic knowledge of their specialty, even if that knowledge is somewhat simplified and adapted to the level of what can be accessible and fully comprehensible to students in the early years of their university studies.

The word systemic, or systematized, is the key in this case because otherwise (if the professional knowledge that students obtain in the target language is fragmentary and disconnected - as it is in many ESP courses now) only disparate fragments may be associated in learners' consciousness with professional communication in that language. The absence in their consciousness of harmonious, professionally systematized 'picture' of target language professional communication cannot but stand in the way of effective and efficient development of professional target language communication skills. This is one of the reasons why developing skills of fluent professional communication in English often takes longer and is more difficult in university ESP courses than it could be if such skills were initially developed on the basis of sound and systematized professional knowledge that itself was acquired through the medium of the target language.

What has been said means that an ESP course for future economists and businesspeople must be designed as a simplified course of Economics and/or Business taught in English; an ESP course for future practical psychologists - as a simplified course of Practical Psychology in English; an ESP course for future architects - as a simplified course of architecture in English, etc. 
Writing a coursebook of English for professional purposes for such a course presupposes first of all the selection of its professionally systematized content parts, and attaching to each of those parts relevantly selected professional themes/topics (the theme-based instruction).

For instance, the ten themes/topics selected for the ESP course for future psychologists and listed in Chapter 2 of this monograph (c.f. section 5.2.1 in that chapter) were attached to four principal parts of the course, each part embracing two or three themes/topics. In the final version of the course and the coursebook Psychological Matters for the course those parts were presented as four separate modules:

MODULE 1. PSYCHOLOGY, ITS BRANCHES, AND HISTORY

THEME 1. Psychology and its Branches

THEME 2. History of Psychology

MODULE 2. PSYCHOLOGICAL CHALLENGES AT WORKPLACE

THEME 3. Job Burnout

THEME 4. Balancing Work and Family

THEME 5. Psychology of Employment and Working Place Conflicts

MODULE 3. THE PSYCHOLOGY OF INDIVIDUAL DIFFERENCES

THEME 6. Managing Emotions and Feelings

THEME 7. Personality and Individual Differences

MODULE 4. PSYCHOTHERAPY AND PSYCHOLOGICAL COUNSELLING

THEME 8. Psychotherapy

THEME 9. Gestalt Therapy

THEME 10. Psychological Counseling.

Naturally, such systematized content parts, just like the themes (c.f. Chapter 2), could not be selected by specialists in foreign language teaching (the authors of the coursebook) by themselves. Specialists in Psychology had to be addressed and, for that purpose, practical psychologists participating in our questioning described in Chapter 2 (c.f. 5.2.1) as well as the professors and teachers from the Department of Practical Psychology at Alfred Nobel University in Dnipropetrovsk were consulted.

It was those professors and teachers who recommended making the first part (module) in the coursebook and the course an introductory one dealing with the general definition of what Psychology is, what its branches are, and the history of its development in the last one hundred years. All our consultants were confident that such a module is required for letting students develop a general idea about their future profession, though the content materials in that part are only indirectly connected with the professional activities of a practical psychologist.

On the contrary, the other three parts (modules) are devoted only to practical professional activities and embrace them quite fully and in quite a systematized 
manner. The second and third parts (modules) are devoted to the most frequent psychological problems that practical psychologists have to deal with in their work: workplace problems and emotional problems, both kinds of problems being inextricably intertwined with human personalities and people's individual differences. Finally, the last part (module) familiarizes students with those psychological tools that practical psychologists have at their disposal for treating those psychological problems that they were studying while working on parts (modules) 2 and 3 .

It seems self-evident but should, however, be mentioned that only after the content parts (modules) for the ESP coursebook and the ESP course are selected can the selection of themes for every part following the methodology analyzed in Chapter 2 (section 5.2.1) start.

In quite an identical manner to the one discussed above, when preparing the coursebook Business Projects, six principal content parts of the course presented as its six modules were first selected, and later twelve selected themes/topics were attached to them:

\section{MODULE 1. STARTING A BUSINESS}

THEME 1. Forms of Businesses

THEME 2. Company Structure

MODULE 2. JOB HUNTING

THEME 3. Making an Appointment and Applying for a Job

THEME 4. Career Profiles. Job Interviews

MODULE 3, BUSINESS ENVIRONMENT

THEME 5. Domestic and World Economy

THEME 6. Business Objectives, Strategy, and Competition

MODULE 4. MARKETING AND PRODUCTION

THEME 7. Marketing

THEME 8. Production

MODULE 5. Banking and Finance

THEME 9. Banking

THEME 10. Financing

MODULE 6. FAIRS, EXHIBITIONS, CONTRACTS

THEME 11. Participation in Fairs and Exhibitions

THEME 12. Contracts

In this case, all the parts (modules) and themes are connected with Business Studies and practices in business: founding a business, seeking employment in some business, defining business objectives and strategies, competition in business and ways of dealing with it, the financial issues of conducting a business, business contracts, marketing, promoting, and advertising, etc. Although the ESP coursebook in question (Business Projects) and the ESP course were aimed at stu- 
dents of Economics and Business (which is one and the same major at Ukrainian universities), the focus was mostly placed on business and not on economics. Only one of the themes in part 3 Domestic and World Economy is directly connected with the issues of Economics, all the other parts are Business Studies only. That was done on the advice of specialists in the field. They believed in the rationality of just such an approach because most graduates in Economics and Business from Ukrainian universities pursue careers in business. This is why the aim was to provide students with 'a big target language picture' of Business Studies much more than with that of Economics. And it may be safely asserted that in what concerns the representation of Business Studies and professional business activities in the above list of selected parts (modules) and themes, they were represented in a sufficiently complete and systematized manner. All the basic aspects of conducting a business - beginning from its establishment and including all the fundamental aspects of its functioning - were covered in quite a full and logical sequence.

The above examples of practical functioning of the principle of systematizing the professional information in ESP coursebooks and ESP courses demonstrate that the principle under discussion practically regulates the selection of the informational aspect of learning content by way of governing the selection of learning modules and themes for organizing content-based instruction. Such regulation allows making the selection professionally relevant and quite logical from the professional point of view - thus creating a sound, professionally justifiable foundation for the following stages of learning content selection.

The next principle to be considered in the second section of this chapter is the principle of authenticity of students' learning activities and learning communication. This is to be the next one because it regulates, among other things, the choice of communicative situations which is the next step in learning content selection after choosing professional themes for learning (the choice of which is governed by the principle that has just been analyzed).

\section{The principle of authenticity of students' learning activities and learning communication}

This principle is fully based on and serves the practical implementation of such a fundamental constituent of the constructivist approach as experiential interactive teaching/learning. The principle means that the entire teaching/learning process is supposed to be designed as students' communication in English on professional issues, this communication to be organized in the framework of learning activities that accurately model authentic professional activities and authentic professional communication of a future specialist. The professional communica- 
tion in such a case is called upon to reflect the professional situations in which a future specialist may with the greatest probability need communicating in English for solving professional tasks. In addition, following the principle discussed before (that of systematizing the professional information in ESP coursebooks and ESP courses), such situations are supposed to ensure professional communication on the professional topics (themes) selected for the ESP course.

In accordance with the above definition, the practical implementation of the principle of authenticity of students' learning activities and learning communication is totally dependent on communicative situations selected for the teaching/learning process because it is on the basis of such situations that different learning activities are organized. On the one hand, those situations are most certainly selected taking full account of the themes (topics) of professional communication chosen for teaching and learning in a definite ESP course (c.f. Chapter 2, 5.2.1). But on the other hand, for adequately selecting such situations, besides the themes (topics), it is also necessary to take into consideration the probability for a specialist (university graduate) in a certain field of having the need in professional target language communication in this or that professional communicative situation. Such a probability can be taken account of in the situation selection process only on the basis of consultations with specialists in a certain professional field who have a good command of the target language and frequently use it in their professional activities. Only they can competently decide which professional communication situation is quite probable to require target language communication in it, and should, therefore, be included into the list of professional communicative situations (and which situation is much less probable and may be omitted from that list).

In Chapter 2 (5.2.1) the procedure of communicative situations selection on the basis of consultations with specialists has already been discussed. There, the list of selected communicative situations for an ESP course designed for future economists and businesspeople was also demonstrated as the one exemplifying the results of using the suggested selection procedure. Not to return to that list again, in this section the list of communicative situations selected for an ESP course for future psychologists is given below. But such a list, unlike the previous one, is quoted in its full version, i.e., with indications of the type of communicative activities (reading, speaking, listening, or writing) for developing skills in which this or that situation has been selected, and with identifying the kinds of experiential learning activities that are designed to develop such skills. Thus, the list below is also meant to show which kinds of learning activities are considered as authentic for developing target language professional communication skills.

The list in question (of professional communicative situations in connection with communicative activities to be taught and learning activities used for teaching skills in those activities) includes a number of components. The components are subdivided into five parts: four parts in accordance with four principal types 
of target language communicative activities (reading, speaking, listening, and writing) to be taught and one part for integrated teaching of reading, speaking, listening, and writing. These communicative activities to be taught form something like headings for five separate lists of communicative situations and learning activities. Every entry under such a kind of heading contains a description of the situation which, at the same time, represents the learning activity planned for using in such a situation.

\section{For teaching reading:}

1. Information search (library search - optional, if the university's library possesses sufficient number of authentic sources in English from the fields of students' majors; Internet search - obligatory) as a foundation for students' completing different profession-related speaking and writing learning tasks in English.

2. Reading various authentic printed profession-related English texts (in the ESP coursebook and from other printed sources) on theoretical and practical issues of students' majoring discipline(s) for doing on the basis of the information obtained different tasks connected with the analysis of that information, completing various creative tasks such as presentations, projects, development of cases, etc.

3. Reading various authentic electronic profession-related English texts (found on the Internet) on theoretical and practical issues of students' majoring discipline(s) for doing on the basis of the information obtained different tasks connected with the analysis of that information and for completing various creative tasks.

\section{For teaching speaking:}

1. Students' preparing and delivering in English different kinds of presentations, talks, and reports on the issues of their future professional activities.

2. Discussing cases when students are requested to give professional recommendations on the basis of initial information supplied to them.

3. Brainstorming and professional discussions on theoretical and practical profession-related issues.

4. Simulating (role-playing) different situations of professional communication in English - that communication being the means for completing various kinds of modeled profession-related activities.

\section{For teaching listening:}

1. Listening to authentic short professional lectures, presentations, talks, reports in English on different profession-related theoretical and practical issues; completing on the basis of the information obtained different profession-related tasks connected with the analysis of that information. 
2. Listening to fragments and passages from authentic professional communication in English (discussions, consultations, etc.) where different professional issues are negotiated. Listening is done for obtaining information with the purpose of completing on the basis of that information various information analysis tasks as well as other creative tasks in speaking and writing.

3. Listening (with the same purpose as above) to authentic professional information in English found in the process of Internet-search (e.g., using YouTube video materials on professional Internet sites in English).

\section{For teaching writing:}

1. Writing abstracts and essays on theoretical and practical issues of students' future professional activities.

2. Writing summaries of professional texts/materials in English that students have read or listened to.

3. Writing short articles on professional issues, especially in the framework of students' project work.

4. Writing professional cases by students themselves - those cases to be discussed in the process of class work.

5. Writing the texts and notes for students' own oral presentations, talks and reports to be delivered in the framework of doing different learning tasks.

\section{For integrated teaching of reading, speaking, listening, and writing}

1. The situations of doing different kinds of profession-oriented learning projects. In this case, reading or listening done when collecting materials for the project are necessarily followed by speaking (and listening) with the aim of discussing the materials found and their usefulness for the project. This is followed by equally unavoidable and obligatory writing (preparing the project's intermediate or final products) which is again followed by speaking and listening (discussion of the product). Such discussions may, in their turn, entail further reading (for improving the product), etc.

Analyzing the kinds of learning activities enumerated in the list above, several conclusions, which, in fact, lie on the surface, can immediately be drawn:

1. All the selected communicative situations genuinely model the authentic professional communicative situations in which a practical psychologist may really need to communicate in the target language. For instance, the most frequent of such situations is the search for information, especially searching for professional information on Internet sites in English. Another frequent situation is the discussion of some professional issues with foreign colleagues when English is the only possible common language for communicating. The third situation of quite a common occurrence 
is listening to talks, reports, or lectures when attending professional conferences abroad, etc. All such situations of professional communication in the target language are indeed quite typical for the career of a practical psychologist, i.e., they reflect the need in communicating in English for professional purposes with a high degree of probability and are authentic from the professional point of view.

2. The learning activities that are used in the framework of such situations practically coincide with the situations themselves. For instance, writing the texts and notes for students' own oral presentations, talks and reports to be delivered is both a situation and a learning activity. On the one hand, a situation in which a future professional may find himself/herself in the course of his/her professional career (the necessity of getting prepared for giving a talk in English at a professional conference abroad) is faithfully modeled. On the other hand, the kind of professional activity that $s /$ he will have to be engaged in when finding himself/herself in such a situation (writing notes or the full text of the talk to be delivered as a means of getting adequately prepared for such a talk) is no less faithfully modeled as well. In this way, not only the situations, but also learning activities and learners' professional communication in English when doing such activities are professionally authentic - which is what, in fact, the principle under consideration means.

3. All the learning activities enumerated in the lists above belong to the experiential interactive ones discussed in Chapter 1 and those lists in their entirety actually embrace all of them. This shows that the implementation of the principle of authenticity of students' learning activities and learning communication is indeed aimed at practically supporting the experiential interactive teaching/learning constituent of the constructivist approach to designing an ESP course.

4. All the learning activities involved are oriented at learners' involuntary acquisition and reinforcement of target language vocabulary, grammar, and pronunciation. Most certainly, it does not mean that special exercises specifically aimed at students' learning vocabulary and grammar and developing appropriate language skills are totally excluded from the course. They are included in the Workbook to students' coursebook (c.f. examples from Chapter 1, section 3.2) for doing them in learners' outof-class work. But students are never engaged in such activities in class where only experiential and totally communicative learning activities are used in accordance with the requirements of the constructivist approach.

5. The suggested situations have been selected with the view of designing an ESP course for future practical psychologists. They may and, most probably, will be different when selecting them for students having different majors in their university studies. It means that there can be 
no universality in the process of selecting communicative situations for tertiary students of different majors. In each particular case, the selection process should be done separately.

Having discussed the implementation and meaning of the principle of authenticity in organizing students' learning activities and learning communication, the next principle for consideration that seems to be the closest to the two principles already discussed is the principle of authenticity of learning materials. Its closeness to the principles of systematizing professional information in the coursebook and course of English for Specific Purposes and of authenticity of students' learning activities and learning communication is due to the fact that all the three principles are responsible for the practical implementation of content-based instruction. As already said, the principle of systematizing professional information in the coursebook and course of English for Specific Purposes is responsible for adequate selection of professional informational content parts and professional themes for an ESP course while the principle of authenticity in organizing students' learning activities and learning communication is responsible for selecting professional communicative situations (though not only for that - see above). The principle of authenticity of learning materials is responsible for continuing such content selection - it is charged with the proper selection of speech materials and samples and all the other learning materials for an ESP course. Besides, the principle in question is most closely connected to the principle that has just been discussed - that of authenticity of learning activities and learning communication. This is because authentic learning activities naturally require authentic learning materials for their organization. Otherwise, they cannot be genuinely authentic. This is why the principle of authenticity of learning materials is the one next in line for analysis.

\section{The principle of authenticity of learning materials}

This principle is the practical continuation of the theme-based approach to learning content selection and ESP course design. As already mentioned, the principle is responsible for the adequate selection of all learning content (except the themes and communicative situations) beginning from speech materials and samples to be used in the teaching/learning process. As it is clear from the principle's name, it means that all learning materials, and primarily the speech materials and samples, are supposed to be authentic. The authenticity of materials is considered as an absolutely indispensable prerequisite of successful ESP teaching and learning because otherwise (and that has also been reiterated in the preceding pages) students will miss the opportunity of learning from 
authentic professional target language communication samples. But such a definition of the principle requires the explanation of how authenticity is understood in this case.

Speech/communication materials (first of all, texts for reading and listening) in language studies are usually termed authentic if they are prepared (written or recorded) by native speakers for native speakers and originally were not meant at all for teaching and learning purposes in the process of second/foreign language studies (Nuttal, 1996). In accordance with this definition of authenticity, professional English texts for ESP students' reading can be said to be authentic if they were originally prepared by native speakers, specialists in the given field, for other native speakers, also specialists in that field. In the same way, an audio recording of a psychological session in English is an authentic material for ESP students majoring in Psychology if the session was conducted by a native speaker psychologist and recorded for information or use by other specialists in psychology who are also native speakers. If this condition of authenticity is not fulfilled, i.e., if texts for reading and/or listening are artificial-specially prepared by the author of a coursebook or some other compiler of teaching/learning materials, - they cannot be considered as reliable samples and reliable sources of speech materials for teaching students.

Naturally all materials, even authentic, at once become learning materials if they are selected for teaching ESP students. But that in no way influences their authenticity. Fortunately, nowadays there is no problem in selecting authentic learning materials thanks to the Internet which is an inexhaustible source of them. One more, and very important, source of authentic learning materials are textbooks on students' majoring subjects published in English-speaking countries for native speaking students who study those subjects at universities in such countries in the framework of their professional training.

However, whatever the sources and origins of such authentic materials are, they should be classified according to their type in the ESP teaching/learning process. Following that classification, the learning materials can be divided into genuine, adapted, and synthesized (Trimble, 1992).

Genuine learning materials, according to Trimble (1992), are those taken from authentic contexts without any changes.

Adapted materials are those that are based on authentic ones but that have certain changes made in them - as a rule, those changes having been made with the purpose of simplifying the materials. In this way, adapted materials do not in fact adequately reflect genuine native speakers' communication samples. The same, by the way, concerns the materials that may be called created, or modeled (Barabanova, 2003: 13). They are texts specially written for ESP teaching purposes without direct support from original authentic professional texts.

Finally, the last category of texts used for ESP learning purposes may be called synthesized ones. They are completely authentic and directly borrowed from au- 
thentic sources. But their distinctive feature is due to the fact that the compiler of learning materials synthesizes one text out of several ones - two, three, or even more. One coherent and cohesive text is structured out of several authentic ones by using certain procedures discussed below. The procedures are such that they help to preserve the authenticity of the compiled text for reading or listening created thanks to using them. At the same time, the material is made more suitable to teaching/learning conditions and purposes (for instance, the text is made not adapted but adjusted - see the explanation below - to the students level of target language proficiency or to the learning content, such as themes, being learned, or to the goals at this or that stage of learning, etc.).

The transformation of some original authentic professional target language materials (texts) into a synthesized material (text) to be used for ESP teaching/ learning purposes can be achieved using several methods:

1. merging-combining several authentic professional texts into one so that the text obtained as a result of such synthesis better covers some learning theme (topic) or communicative situation(s) and, thanks to that, becomes better suited to the teaching/learning goals at a definite stage of learning;

2. abridging (which practically always follows merging) - cutting out a number of less important parts (paragraphs, fragments, etc.) of the original texts so that the obtained synthesized text is not too large for using it in the teaching/learning process;

3. adjusting as to content and language - cutting out a number of parts (paragraphs, fragments, even separate sentences and words) that may be too difficult for students to understand either due to their content or due to their language characteristics; such cutting out can be done only if the basic content and meaning of the original texts being synthesized remain intact;

4. linking - using special language means to join together the texts being synthesized and/or the parts of those texts from within which some fragments have been cut out (a paragraph in the middle of which a sentence has been cut out, two paragraphs out of original three when the middle paragraph has been cut out, etc.). Such linking means inserting some linking words, sentences, or even short paragraphs written specially for that purpose by the compiler of teaching/learning materials. Linking is required for restoring or renewing the internal structure of the synthesized text so as ensure the unity, coherence, and cohesion of the obtained final text planned for using in the teaching/learning process.

An example of such a synthesized text is given below. It is one of the texts for reading used in the ESP course for future psychologists. The text serves as a starting point for students to do several kinds of reading and writing learning tasks. It is placed in the coursebook Psychological Matters by Tarnopolsky, Kozhushko, et al. (2011a) in the Workbook to Unit 2. History of Psychology. 


\section{What Is Social Psychology?}

According to psychologist Gordon Allport, social psychology is a discipline that uses scientific methods «to understand and explain how the thought, feeling and behavior of individuals are influenced by the actual, imagined, or implied presence of other human beings» (1985).

Social psychology looks at a wide range of social topics, including group behavior, social perception, leadership, nonverbal behavior, conformity, aggression, and prejudice. It is important to note that social psychology is not just about looking at social influences. Social perception and social interaction are also vital to understanding social behavior.

The U.S. government became interested in applying social psychological concepts to influencing citizens. Social psychology has continued to grow throughout the twentieth century, inspiring research that has contributed to our understanding of social experience and behavior.

It is important to understand how social psychology differs from other disciplines. Social psychology is often confused with personality psychology and sociology. What makes social psychology different?

While personality psychology focuses on individual characteristics and thoughts, social psychology is focused on situations. Social psychologists are interested in the impact that social environment and interaction has on attitudes and behaviors.

It is also important to distinguish between social psychology and sociology. While there are many similarities between the two, sociology tends to look at social behavior and influences at a very broad-based level. Sociologists are interested in the institutions and culture that influence social psychology. Psychologists instead focus on situational variables that affect social behavior. While psychology and sociology both study similar topics, they are looking at these topics from different perspectives.

The ideas of Lev Vygotsky have greatly influenced both cognitive and social psychology. The work of Lev Vygotsky (1896-1934) has become the foundation of much research and theory in cognitive development over the past several decades, particularly of what has become known as Social Development Theory. Vygotsky's theories stress the fundamental role of social interaction in the development of cognition, as he believed strongly that community plays a central role in the process of "making meaning".

(Based on the texts: What Is Social Psychology? by Kendra Cherry and Vygotsky by Saul Mcleod retrieved from http://psychology.about.com/od/ socialpsychology/f/socialpsych.htm and http://www.simplypsychology.pwp. blueyonder.co.uk/vygotsky.html as of December 3, 2008)

The text above was synthesized from two texts retrieved from two different Internet sites - both devoted to psychological issues (at the time of writing this monograph those texts were still available on the sites indicated above and below). The original authentic texts that were used for synthesizing are given in full as an illustration: 


\section{What Is Social Psychology?}

By Kendra Cherry, About.com Guide

According to psychologist Gordon Allport, social psychology is a discipline that uses scientific methods «to understand and explain how the thought, feeling and behavior of individuals are influenced by the actual, imagined, or implied presence of other human beings» (1985).

Social psychology looks at a wide range of social topics, including group behavior, social perception, leadership, nonverbal behavior, conformity, aggression, and prejudice. It is important to note that social psychology is not just about looking at social influences. Social perception and social interaction are also vital to understanding social behavior.

\section{Brief History of Social Psychology}

While Plato referred to the idea of the "crowd mind» and concepts such as social loafing and social facilitation were introduced in the late-1800s, it wasn't until after World War II that research on social psychology would begin in earnest. The horrors of the Holocaust led researchers to study the effects of social influence, conformity, and obedience.

The U.S. government also became interested in applying social psychological concepts to influencing citizens. Social psychology has continued to grow throughout the twentieth century, inspiring research that has contributed to our understanding of social experience and behavior.

\section{How Is Social Psychology Different From Other Disciplines?}

It is important to understand how social psychology differs from other disciplines. Social psychology is often confused with folk wisdom, personality psychology, and sociology. What makes social psychology different? Unlike folk wisdom, which relies on anecdotal observations and subjective interpretation, social psychology employs scientific methods and empirical study of social phenomena.

While personality psychology focuses on individual traits, characteristics, and thoughts, social psychology is focused on situations. Social psychologists are interested in the impact that social environment and interaction has on attitudes and behaviors.

Finally, it is important to distinguish between social psychology and sociology. While there are many similarities between the two, sociology tends to look at social behavior and influences at a very broad-based level. Sociologists are interested in the institutions and culture that influence social psychology. Psychologists instead focus on situational variables that affect social behavior. While psychology and sociology both study similar topics, they are looking at these topics from different perspectives.

(retrieved at http://psychology.about.com/od/socialpsychology/f/socialpsych. $\mathrm{htm}$ as of December 3, 2008) 


\section{Vygotsky \\ by Saul Mcleod, published 2007}

The work of Lev Vygotsky (1896-1934) has become the foundation of much research and theory in cognitive development over the past several decades, particularly of what has become known as Social Development Theory.

Vygotsky's theories stress the fundamental role of social interaction in the development of cognition (Vygotsky, 1978; Wertsch, 1985), as he believed strongly that community plays a central role in the process of «making meaning.»

Unlike Piaget's notion that children's development must necessarily precede their learning, Vygotsky argued, «learning is a necessary and universal aspect of the process of developing culturally organized, specifically human psychological function» $(1978$, p. 90). In other words, social learning tends to precede (i.e. come before) development.

Vygotsky has developed a socio-cultural approach to cognitive development. He developed his theories at around the same time as Piaget was starting to develop his theories (1920's and 30's), but he died at the age of 38 and so his theories are incomplete - although some of his writings are still being translated from Russian.

No single principle (such as Piaget's equilibration) can account for development. Individual development cannot be understood without reference to the social and cultural context within which it is embedded. Higher mental processes in the individual have their origin in social processes.

\section{Vygotsky's theory differs from that of Piaget in a number of important ways:}

1: Vygotsky places more emphasis on culture affecting/shaping cognitive development - this contradicts Piaget's view of universal stages and content of development. (Vygotsky does not refer to stages in the way that Piaget does).

2: Vygotsky places considerably more emphasis on social factors contributing to cognitive development (Piaget is criticized for underestimating this).

3: Vygotsky places more (and different) emphasis on the role of language in cognitive development (again Piaget is criticized for lack of emphasis on this).

(retrieved at http://www.simplypsychology.pwp.blueyonder.co.uk/vygotsky.html as of December 3, 2008)

If the two quoted original texts are compared with the text preceding them which was synthesized for teaching/learning purposes, it can be seen that all the four methods of synthesizing were used in that case:

1. Merging - two absolutely different and separate texts (even from different web-sites) were combined to form a single new text that best corresponds as to content matter to what is to be studied in the ESP course on the sub-topic "Social Psychology" in the framework of the theme "History of Psychology". 
2. Abridging - entire paragraphs were cut out from both original texts (from the second text only two first paragraphs were left) to make the size of the final synthesized text suitable for learning purposes.

3. Adjusting-some word combinations and even sentences that presented unnecessary vocabulary for students were cut out (e.g., the word combination folk wisdom in the second sentence of the fifth paragraph in the first original text). In the same way, entire paragraphs were cut out if they presented unnecessary content matter from the point of view of what subject matter had been selected for that particular ESP course (e.g., the following paragraph from the first original text: "While Plato referred to the idea of the "crowd mind" and concepts such as social loafing and social facilitation were introduced in the late-1800s, it wasn't until after World War II that research on social psychology would begin in earnest. The horrors of the Holocaust led researchers to study the effects of social influence, conformity, and obedience').

4. Linking - adding words or sentences to link the parts of the new synthesized text in a logical, coherent, and cohesive manner (e.g., the sentence "The ideas of Lev Vygotsky have greatly influenced both cognitive and social psychology" had not been in the original text but was inserted later into the synthesized text for logical connection's sake).

In this way, the synthesized text "What Is Social Psychology?" loses nothing of the authenticity of the original ones but has become quite suitable for learning purposes. Thus, synthesizing allows for the creation of new materials in what concerns a number of their features as compared with the existing ones from which they were synthesized. Those new features are such that make the materials obtained in the process of synthesizing better suited for the conditions and requirements of learning, at the same time leaving intact the authenticity of those materials. (It should be remarked in brackets that if the original texts are copyrighted, synthesizing them in the way shown above certainly requires the permission of the copyright holder. If there are no copyright indications - as it is often the case with the materials from the Internet, like the ones above, - when using them for learning purposes by way of synthesizing, it is absolutely required to clearly quote the sources where the original materials to be subjected to synthesizing had been found - see the examples above.)

From everything said above it becomes clear that, if the requirement of employing authentic materials in ESP courses is accepted, adapted and created/ modeled materials (texts) cannot be used in the constructivist teaching/learning process. Their lack of authenticity cannot provide ESP students with a reliable model and reliable samples of professional target language communication. Only genuine and synthesized materials, having authenticity as their distinctive feature, are acceptable for creating such a model and samples. Of these two, the latter types of teaching/learning materials, the synthesized ones, are more suitable for 
students' learning needs and possibilities, so they may be used in considerably greater numbers than the genuine ones. It is because of that reason that both our coursebooks discussed in this monograph (Business Projects and Psychological Matters) were mostly designed on the basis of synthesized materials. But of course, when students are selecting their own materials in English, for instance in the process of Internet research, they are dealing with genuine materials only, so that there is always a balance between genuine and synthesized authentic professional materials in the ESP teaching/learning process.

Actually, when authentic speech materials and samples (genuine and/or synthesized) have been selected, the principle of authenticity of learning materials, which is under consideration in this section, starts governing the selection of all the other parts of learning content only indirectly. This is because those other parts (vocabulary, grammar, sociolinguistic and pragmatic information, communication and language skills) are selected from and/or on the basis of speech/ communication materials and samples - taking into account the previously selected themes and situations of professional communication. That was discussed in details in Chapter 2 where the procedure of such selection was described.

With this remark, the analysis of the principle of authenticity of learning materials may be finished while the principle of integrating English speaking, listening, reading, and writing in the learning process comes up next for consideration.

\section{The principle of integrating English speaking, listening, reading, and writing in the learning process}

This principle, together with the principle of authenticity of students' learning activities and learning communication, serves to ensure adequate practical implementation of experiential interactive learning as the fundamental feature of the constructivist approach.

For ESP courses the importance of this principle is much greater than for courses of General English. This is because in professional activities of a specialist the four basic types of communicative activities are naturally integrated due to professional requirements. For instance, a person engaged in business in the course of business talks (listening and speaking) has to read some documents and his/ her notes (reading), write some other notes on the basis of which, after the talks, the text of an agreement may be drawn (writing). Drawing the agreement (writing) may require getting familiarized with relevant documentation (reading), additional consultations with partners over the telephone (listening and speaking) or via e-mail (writing), etc. In a similar manner, a practical psychologist, after hav- 
ing finished a consultation or a session with a client (listening and speaking), usually writes notes of that session for further reference and/or for sharing with colleagues (writing). S/he may need looking up similar cases in professional literature (reading) and then discuss the particular case of his/hers at a seminar with colleagues (speaking and listening), etc.

Such integration of speaking, listening, reading, and writing in professional activities (the integration being manifested through organic and obligatory links and transitions from one kind of communicative activity to all the others) has to find its reflection in the process of ESP teaching and learning if that teaching and learning is planned to be designed on the basis of the constructivist approach. This is because the constructivist approach requires professional activities to be modeled as accurately as possible in every ESP course. The principle of integrating English speaking, listening, reading, and writing in the learning process is designed to guarantee such modeling of that important aspect of professional communication.

In fact, within the framework of the constructivist approach, it is experiential interactive teaching/learning in particular that requires modeling professional activities in an ESP course to be as accurate as possible. Therefore, the principle of integrating English speaking, listening, reading, and writing in the learning process, by giving an opportunity of more accurate and complete modeling of professional activities in an ESP course, fulfills one of the basic requirements of experiential interactive teaching/learning process organization. It also helps to fulfill a general requirement that has long been admitted as quite important for teaching English as a second/foreign language - that of integrating communicative activities in such teaching (Byrne, 1987; Oxford, 2001; Weissberg, 2009).

The implementation of the principle under discussion in teaching practice can be illustrated by presenting a scheme of consecutive order of learning tasks given to students in a typical unit from the coursebook Psychological Matters (Tarnopolsky, Kozhushko, et al., 2011a).

In that coursebook, the work on every unit begins with students discussing the issues (speaking and listening) which are connected with the theme (topic) of the unit. That allows revealing learners' background knowledge. On the basis of their discussion, the students proceed to reading one or several texts with professional content of the text(s) related to the issues that have just been discussed, so that the materials being read might help learners to clarify their own ideas on the topic under analysis (reading). A new discussion follows reading - to compare and contrast the ideas formulated by students themselves and the ideas in the text(s) read (speaking and listening). After that, the information obtained is replenished by way of giving learners opportunities of listening to audio materials where the same professional issues are debated in various practical manners - listening to recordings of psychological sessions, descriptions of cases, short lectures, etc. (listening). What has been heard is also discussed (speaking and listening), and the students proceed to generating/producing their own infor- 
mation - for instance, developing their own cases, preparing presentations on the issues under consideration, etc. (reading and/or listening when searching for information, speaking/listening when discussing what has been found or what has been developed with the other students and the teacher). Finally, the endproduct of students' efforts is always presented in the written form: an essay or a summary, a project report or an article, etc. (writing).

From the above scheme of teaching/learning process organization it can be seen how organic and natural the transitions from one type of communicative activity to the others are: the transitions from speaking/listening to reading, from reading again to speaking/listening, from there to listening to recordings of audio materials, thence to reading, listening and speaking again, and finally, to writing (see above). The organic character and naturalness of the transitions are conditioned by the nature of learning tasks received by students.

To emphasize the point made in the preceding paragraph, it is also worth demonstrating an actual series of learning activities from the coursebook Business Projects (Tarnopolsky, Kozhushko, et al., 2002). Those learning tasks/activities are in most respects similar to the one indicated in the scheme above and they, by themselves, integrate all the four communicative activities in such a manner that each of them is a logical and necessary continuation of the preceding one and a foundation for the following one.

The series of tasks to be demonstrated as an example consists of five learning activities that are taken from Unit 9. Banking and Finance in the coursebook Business Projects (Student's Book):

\section{As you know, banks focus their work on money and financial services. What do you think banks do with their money? Discussing the matter in pairs, list those activities and then report your opinions to the class.}

\section{Read the text and check your answers in activity 2 (above) (8 min.).}

There are two types of banks: commercial banks and investment banks - or merchant banks as they are called in Great Britain. Commercial banks deal mainly with individual customers, for instance, private citizens, small businesses, and such like. They receive and hold deposits, lend money, exchange foreign currencies, advise their customers how to invest their money, and manage the customers' accounts (for instance, pay or invest money according to the customer's wishes). Commercial banks make their profit from the difference between the interest that they pay to people who deposit money and the interest they charge to people who borrow money. This difference is called a margin.

Investment banks deal mainly with rich corporate clients (companies or large firms) or rich individual clients. They aim not so much at lending money but at raising funds for industry (their corporate clients) in different financial markets. Therefore, investment banks act mainly as intermediaries for their customers. They do 
not themselves make loans, but make their profits from fees paid for their services. Merchant banks in Britain do the same, but they have greater authority because they also offer loans themselves. They finance international trade, deal with mergers, and issue government bonds.

In recent times, the difference between commercial and investment banks has been slowly disappearing as the so-called "financial supermarkets" replace them. These are a combination of a commercial bank, an investment bank, and an insurance company, offering the full range of financial services.

Whether depositing or borrowing money, a customer is most interested in the bank's interest rate. The minimum interest rate within a certain country is usually determined by the central bank, and the interest rates offered by other banks sometimes fluctuate slightly from time to time, and are publicly advertised by any bank. They are always either higher than or equal to the minimum interest rate fixed for that country.

3. Role-play (in pairs). The text above described the banking system in English speaking countries. You are having an exam at a Business School now.

\begin{tabular}{|l|l|}
\hline \multicolumn{1}{|c|}{ Student A } & \multicolumn{1}{c|}{ Student B } \\
\hline $\begin{array}{l}\text { You are a professor at a Business } \\
\text { School. Ask your student questions } \\
\text { about the banking system in the USA } \\
\text { and Great Britain. }\end{array}$ & $\begin{array}{l}\text { You are a student taking an exam } \\
\text { professor's questions on the banking } \\
\text { system in the USA and Great Britain. }\end{array}$ \\
\hline
\end{tabular}

4. Continuous simulation. Divide the class into two equal groups. One group discusses the possibility of your company's founding its own bank. This group should find arguments both in favor of opening the bank and for selecting a certain type of bank (commercial, investment, or a financial supermarket). The other group should also discuss the same possibility, but it should find arguments against opening any kind of bank by your company. You have 20-25 minutes for discussion and may ask for your teacher's help in case of difficulties.

5. Project work. Each group should summarize in writing the results of their discussion and their arguments (100 words). This summary will serve as the basis for a presentation in the last class on this unit, and so should be written before then.

It can be seen from the examples of five learning tasks/activities above that speaking and listening in the first one (discussion) naturally lead to reading in the second task, which is absolutely necessary because students need to check the correctness of their ideas formulated in the discussion. Likewise, reading naturally 
leads to speaking and listening again - first, in role playing where students summarize their understanding of the banking system and, later, in continuous simulation where that understanding is used for taking certain practical decisions and finding logical reasons for such decisions. Finally, those decisions and the reasons for taking them are most fully substantiated in writing (project work) that opens up prospects of further speaking and listening in students' presentations.

The given examples demonstrate not only the naturalness of transitions from one learning task to the others tasks connected with developing skills in different target language communicative activities (reading, speaking, listening, and writing). Such naturalness by itself would show only the interconnections and interdependences of reading, speaking, listening, and writing in the learning tasks that students do. But the examples also manifest the ultimate integration of such communicative activities in the teaching/learning process because each of the learning tasks above would become illogical if not preceded or followed by all the other tasks/activities.

So, the examples given are, in fact, an illustration of what was said in section 3.1 of Chapter 1 when discussing how different experiential learning activities contribute to joint (integrated) development of the four basic communicative activities: speaking, listening, reading, and writing. There it was shown how in a constructivist ESP course role plays/simulations, brainstorming, case studies, discussions, students' presentations and project work could never be limited to just one communicative activity but necessarily required engaging students in practically all the others. This is exactly what was exemplified in the series of five learning tasks/activities demonstrated above.

In this way, the analyzed principle of integrating English speaking, listening, reading, and writing in the learning process, on the one hand, ensures full interconnections and interdependences of all the four basic communicative activities and organic natural transitions of one communicative activity into the following ones in the framework of a series of learning assignments/tasks given to students. Thanks to that, the skills in all the four communicative activities develop in a balanced, interconnected, interdependent, and mutually supportive manner. On the other hand, in each one of experiential learning tasks/activities, such as role plays/simulations, brainstorming, case studies, discussions, students' presentations and project work, the four communicative activities are mostly integrated so that one of them naturally requires using the others within one and the same organizational framework. This enhances the interconnected, interdependent, and mutually supportive development of skills in all the four types of professional target language communication.

The completion of discussion of how English speaking, listening, reading, and writing are supposed to be integrated in a constructivist ESP course for tertiary students leaves only the last principle out of five to be analyzed - that of developing learners' informative competence in English. The following section is devoted to that principle. 


\section{The principle of developing students' informative competence in English}

This principle, as said at the beginning of the chapter, means creating the best prerequisites for Internet technologies' use in the teaching/learning process. It certainly pre-supposes the regular and constant use of such technologies in ESP studies. But in fact, that use is not in the area of the principle's responsibilities because it is blended learning itself, as one of the basic features of the developed approach, which is in charge of the organizational aspect of practical Internet involvement in an ESP course.

What the principle of developing students' informative competence in English is really responsible for is ensuring learners' readiness and preparedness for working on the internet with the aim of solving the tasks connected with their ESP studies. This means developing students' competence in using the Internet, which may be called informative competence by analogy with the information technologies in whose structure the Internet occupies the leading position.

It should be noted that the task of a constructivist blended learning ESP course is not developing students' informative competence in general but developing their informative competence in English which has to be formed in case learners regularly and constantly work on Internet sites in English. Those are the only permissible sites to be used in ESP studies while the use of sites in other languages, and first of all in students' L1, must be strictly prohibited in an ESP course. Otherwise, the beneficial effect of using Internet technologies for language acquisition will disappear.

The informative competence in English to be developed by ESP students may be defined as abilities/skills of future professionals to find and use the required professional information through all accessible information channels in English, and first of all, through those that are made accessible thanks to the up-to-date information technologies. Such competence is supposed to be inextricably connected with the students' target language acquisition not only because it is being developed in the framework of an ESP course. The main reason is the fact that, globally, the greater part of professional information, especially in the World Wide Web, is in English (c.f. Graddol, 2006), so that only specialists who possess informative competence in English can gain access to all the wealth of the most recent and important achievements in their respective professional fields.

It may be said that informative competence cannot be limited to using Internet resources only. Even from the definition above it is clear that it should also include abilities/skills of finding the required professional information in all kinds of sources - printed library resources, for example. But in our case, all other information sources, and students' abilities to find the required 
professional resources there, may be disregarded. The task of teaching students how to do, for instance, information research (in English or in other languages) in libraries cannot be listed among the tasks of an ESP course. However, if that course is based on regular and permanent use of Internet technologies (as in the blended learning approach advocated in this monograph), the task of developing students' informative competence in English, at least limited to teaching them how to do Internet research on web-sites in English, cannot be avoided. Not only the learners' future professional competence (in those aspects of it that are connected with using the command of the English language for professional purposes) but also their success in the blended learning ESP course depends on the successful solution of that task. It is hard to expect that students can efficiently work in such a course based on Internet research on web-sites in English if they have not been taught relevant skills of doing such research.

There are two other reasons that necessitate this approach, i.e., including the task of developing ESP students' informative competence in English among the tasks of an ESP course.

The first reason is what was emphasized by Warschauer and Whittaker (1997: 27) whose idea concerning the issue under discussion has already been quoted in Chapter 3 (section 1). They asserted that students not only use the Internet for gaining a better command of English. Sometimes, one of their leading motives for studying English is gaining command of the skills of working on the Internet in English.

The second reason was also identified by Warschauer and his coauthors (Warschaver, Shetzer, \& Meloni, 2000) who stressed the requirement of what they called dual immersion in language studies - meaning that teaching the target language and teaching the use of computer technologies for learning that language should go hand-in-hand in the framework of every language course.

ESP students' informative competence in English presupposes their acquiring at least the following skills without which their Internet research on web-sites in English may hardly be possible:

1. The skill of mostly automatically using the English alphabet letters on the computer keyboard in accordance with their standard layout there.

2. The skill of using the search engines (such as Google and others) in English for the purposes of information search on web-sites in that language.

3. The skill of storing the addresses of web-sites in English that can be used for future studies in computer's memory.

4. The skill of storing and copying the materials found in the process of Internet research (text materials, as well as audio and video materials).

5. The skill of subscribing to mailing lists in English with the aim of receiving the latest professional information. 
If in the teaching/learning process the Internet is used not only for information search but in its other functions that have been discussed in Chapter 3, other skills may also be required. They include (again at the very least):

1. The skills of using e-mail in English (as already said, students should mostly develop such skills even before their ESP course starts).

2. The skills of finding on the Internet and adequately using the programs for learning English autonomously. The programs of that kind are in great abundance there and should be used whenever and wherever possible.

3. The skills allowing students to participate in chat rooms and forums in English where professional issues are discussed.

4. The skills of using the "tandem" method for language learning (when on definite web-sites language learners find partners for mutual help in their learning efforts, as well as tools for such "team" learning (Schmelter, 2004).

Other skills may be listed that could be useful for students to acquire, but the principal point that should be made is that developing the enumerated skills and whatever other skills required for working on the Internet sites in English does not, as a rule, require much time and effort. This is primarily because the greatest majority of university students today (in all countries of the world) already have all the skills listed above - at least, in what concerns working on the Internet in their L1. So, the transfer of those skills for using them on the basis of the English language is mostly a matter of practice. As our experience has shown, the greatest practice, time, and efforts are required for students to get used to the English alphabet letters on the computer keyboard in accordance with their standard layout there. No less important is learning all the English words and names connected with performing the Internet search, subscribing to mailing lists, using chat rooms and forums in English, etc. But again, this is also more a matter of regular Internet practice than of special lessons for teaching such skills.

Certainly, there may always be some students who need such special lessons because of serious inadequacies in the development of their Internet skills. But there should not be many of those lessons - usually two, or even one, two-hour (sometimes one-hour) lessons are enough to give students all the required explanations and let them try out in practice how they can work on the Internet in English. Such short lessons (one or two) may be useful even for students discussed in the preceding paragraph - those who already possess the Internet skills connected with their L1. The lessons may be taught either by an ESP teacher, if $s /$ he is qualified enough to teach them, or by a computer technology teacher-depending on local conditions. After those lessons are held, everything that remains to be done is to provide students with as much practice in using the Internet in English as possible. Therefore, the principle of developing students' informative competence in English does not require a lot of ESP teacher's efforts to be met. But the teacher should always remember about its existence and be 
ready to give students technical help when they are working on the Internet sites in English.

The analysis of the last of postulated principles leaves only one more issue to be discussed in this chapter - that of principles' interconnections.

\section{Interconnections and interdependences of principles underlying the practical implementation of the constructivist blended learning approach}

Such interconnections are shown in Fig. 11 demonstrating all the internal links of the principles in question and their external links to the three fundamental features of the constructivist blended learning approach.

As it can be seen from the scheme in Fig. 11, each of the principles is not only subordinated to one of the fundamental constituents of the constructivist blended learning approach. There are also the relations of interdependence between every principle's own implementation in the teaching/learning process and the implementation of all the other four principles. Those interdependences and relevant interconnections of principles are explained further.

The explanations may begin with the principle discussed in the first section of this chapter - that of systematizing professional information in the coursebook and course of English for Specific Purposes.

It became clear from the analysis in that section that the principle of systematizing professional information in the coursebook and course of English for Specific Purposes is responsible for the selection of such an important part of learning content as future profession-oriented modules and themes to be studied in the teaching/learning process. It is also clear from what was said in Chapter 2 , that the next step in the content selection is the selection of communicative situations. But the practical implementation of their selection depends on a different principle - the principle of authenticity of students' learning activities and learning communication (see section 2 in this chapter). This latter principle regulates modeling professional activities in different kinds of experiential learning activities used in the teaching/learning process. The modeling, to a great extent, depends on communicative situations selected for every such activity, while the selection of those situations themselves is interdependent with choosing the informational parts (modules) and themes for the ESP course (c.f. Chapter 2, section 5.2.1). This is the manifestation of the interdependence of the principle of systematizing the professional information in ESP coursebooks and ESP courses and the principle of authenticity of students' learning activities 
The fundamental features of the constructivist blended learning approach

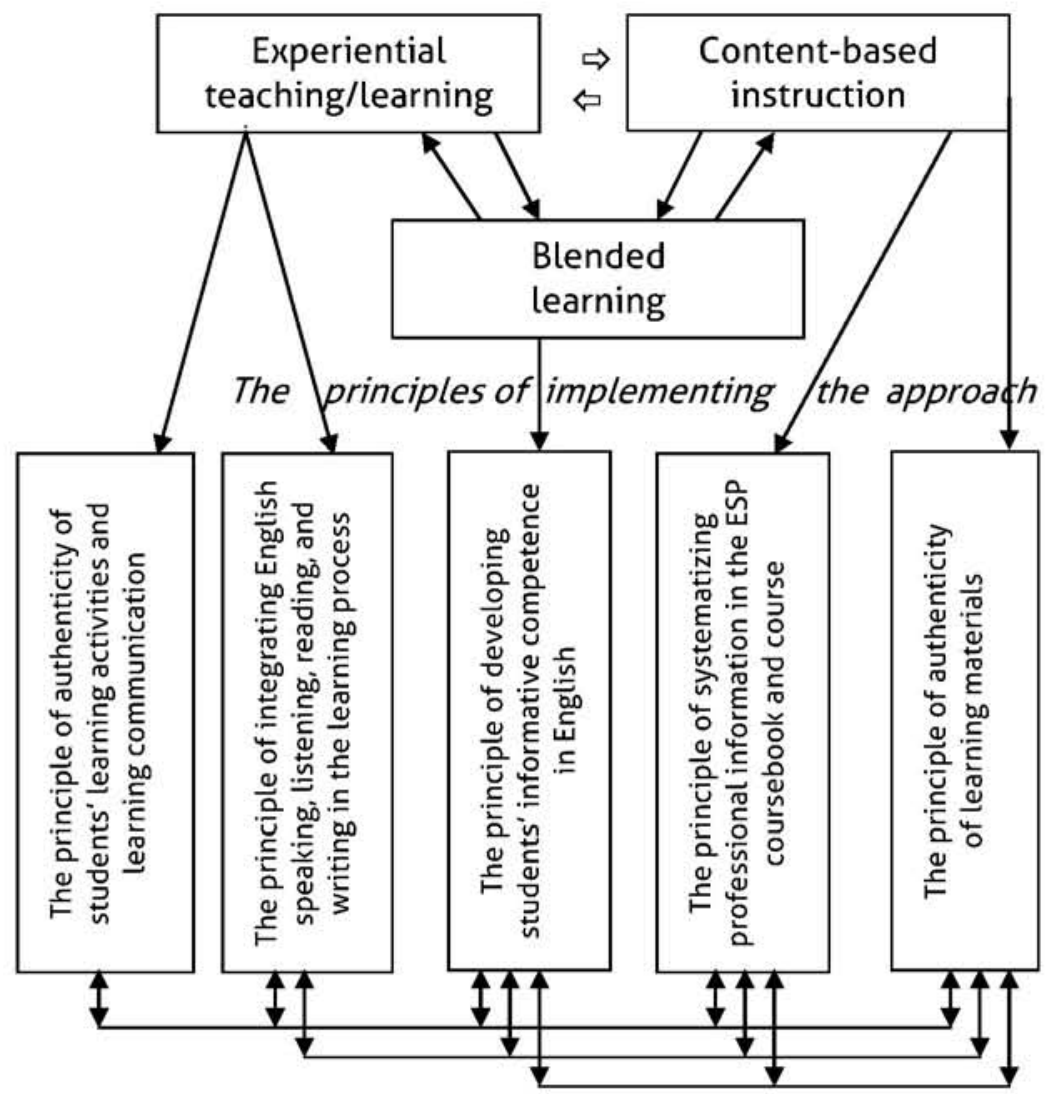

Fig. 11 Links and interconnections of the practical principles for teaching a constructivist blended learning ESP course and the three fundamental features of the constructivist blended learning approach

and learning communication. The interdependence of these two principles has been demonstrated in Fig 11 above by indicating the existing links between them.

There are similar interconnections and interdependences between the principle of systematizing the professional information in ESP coursebooks and ESP courses and all the other postulated principles. The corresponding links are also shown in Fig. 11.

For instance, the links of the principle under consideration with the principle of authenticity of learning materials are quite close. This is due to the fact that the principle regulates, as shown in section 3 of this chapter, the selection of speech/communication materials, samples, and all the other learning content 
chosen from them (c.f. Chapter 2, section 5.2). But the selection of speech/ communication materials is dependent on the selection of themes (the principle of systematizing the professional information in ESP coursebooks and ESP courses) and on the selection of communicative situations (the principle of authenticity of students' learning activities and learning communication). On the other hand, the adequate practical implementation of the latter two principles also depends on how adequately speech materials and the other learning content have been selected. This means that all the three principles discussed above are interconnected and interdependent (Fig. 11).

The principle of integrating English speaking, listening, reading, and writing in the learning process is dependent on the principle of systematizing the professional information in ESP coursebooks and ESP courses too. It is also dependent in a similar manner on the principle of authenticity of learning materials and the principle of authenticity of students' learning activities and learning communication. This is because students' acquisition of target language speaking, listening, reading, and writing skills depends to a great extent on the how adequately themes, communicative situations, speech materials, and other learning content have been selected. But in the same manner, the practical implementation of the principles of systematizing the professional information in ESP coursebooks and ESP courses, of authenticity of learning materials, and of authenticity of students' learning activities and learning communication also depends on what approach to teaching speaking, listening, reading, and writing is followed in the teaching practice. This mutual dependence demonstrates the interconnections of all the four principles in question (Fig. 11).

Finally, quite clear are the interconnections of the four principles discussed above with the last principle of developing students' informative competence in English - the principle responsible for involving the Internet technologies in the teaching/learning process. Since, as shown in Chapter 3 , in the constructivist blended learning approach both the selection of learning content and teaching/ learning that content are inextricably bound with using the Internet technologies, that selection and teaching/learning (i.e., the principles regulating them) depend on the use of those technologies and on the principle governing the ESP students' readiness and preparedness for such use. On the other hand, the use of Internet technologies by even well-prepared ESP students is also quite dependent on how learning content is selected and taught/learned, i.e., on the implementation of the principles regulating such selection and teaching/learning. This manifests the interconnections and mutual dependences of the principle of developing students' informative competence in English and the other four principles.

Therefore, everything said above proves that the suggested principles are not separate entities but form a single system where all component parts, or subsystems, are closely related to each other through a balanced structure of interconnections and interdependences. 


\section{Conclusion to Chapter 4}

In this chapter, five postulated principles responsible for the practical implementation of the constructivist blended learning approach have been discussed and analyzed as to their application to teaching/learning practice:

1. The principle of systematizing professional information in the coursebook and course of English for Specific Purposes. It is responsible for the selection of professionally systematized content parts in an ESP course and for attaching to each of those parts relevantly selected professional themes/topics - thereby serving the practical implementation of the content-based instruction.

2. The principle of authenticity of students' learning activities and learning communication responsible for faithful modeling of their future professional activities and practices in learning activities - thereby serving the practical implementation of experiential interactive teaching/ learning. The principle is also responsible for selecting authentic professionally significant communicative situations in which learning activities are organized to model professional activities most adequately. Therefore, through its responsibility for situation selection, the principle contributes to practical implementation of content-based instruction too.

3. The principle of authenticity of learning materials responsible for the practical implementation of the content-based instruction as well by way of ensuring that learning materials (and primarily speech/communication materials and samples) selected for an ESP course are authentic from the point of view of representing that professional communication in English the skills of which are being taught to students.

4. The principle of integrating English speaking, listening, reading, and writing in the learning process which is in charge of implementing experiential interactive learning by way of modeling one important aspect of professional activities of a future specialist - that of integration in those activities of all the four basic communication skills. The principles ensures full interconnections and interdependences of speaking, listening, reading, and writing and organic natural transitions of one communicative activity into the following ones in the framework of a series of learning assignments/tasks given to students. Thanks to that, the skills in all the four communicative activities develop in a balanced, interconnected, interdependent, and mutually supportive manner. Besides, in each one of experiential learning tasks/activities, such as role 
plays/simulations, brainstorming, case studies, discussions, students' presentations and project work, the four communicative activities are also mostly integrated so that one of them naturally requires using the others within the same organizational framework. This gives one more chance of enhancing the interconnected, interdependent, and mutually supportive development of skills in all the four types of professional target language communication.

5. Finally, the last principle of developing students' informative competence in English which is responsible for creating the best conditions for blended learning implementation by way of ensuring students' acquisition of skills required for successful work on Internet sites in English.

All five principles are interconnected and interdependent, creating a system of basic postulates for practical organization of a constructivist blended learning ESP course. Such an organization is discussed in the last chapter of this monograph. 